\title{
STREET FOOD: CENÁRIOS ENQUANTO INSTRUMENTO DIALÓGICO
}

\author{
Gabriel Gallina \\ UNISINOS \\ arq.gallina@gmail.com \\ Rui Roda \\ UNISINOS \\ rui.roda@me.com
}

Resumo: O artigo tem como objetivo gerar uma reflexão a respeito do uso de cenários como instrumento de design estratégico, bem como as suas particularidades e implicações perante situações que envolvem espaços públicos urbanos, nomeadamente as que estão relacionadas com atividades de street food. Esta abordagem pretende ser coerente com o carácter e utilização espontâneos de práticas não previstas, que representam o tipo de fluxos deste micro empreendedorismo implícito pertencente à natureza do street food. Neste contexto, os cenários apresentam-se como facilitadores do planeamento, do projeto e de mediações no campo do street food, ou seja, tornam compreensível esta relação com a cidade, sua contribuição enquanto tensor de posicionamentos, bem como promotor da visão compartilhada e convergência de objetivos.

Palavras-chave: Cenários; Instrumento de design estratégico; Cidade; Street food.

\begin{abstract}
The article aims at encouraging a reflection on the use of scenarios as an instrument of strategic design, as well as on their specificities and implications in circumstances that involve public urban spaces, namely the ones related to street food activities. This approach is intended to be consistent with the spontaneous character and use of unplanned practices, which represent the type of flows of this implicit micro entrepreneurship and are part of the nature of street food. In this context, scenarios come across as planning, design and mediation facilitators in the street food area, i.e., they make it easier to understand its relationship with the city and its contribution when it comes to tensioning positions and promoting shared visions and convergent goals.
\end{abstract}

Keywords: Scenarios; Strategic design tool; City; Street food. 


\section{INTRODUÇÃO}

Atualmente diversos eventos de comida de rua - as Street food - vêm surgindo nas principais cidades brasileiras. Muitos destes eventos buscam proporcionar uma experiência de convívio e lazer através do consumo de pequenas refeições. As food parties e os food parks, eventos relacionados ao consumo de comida de rua gourmet $\mathrm{e}$ food trucks, estão ganhando popularidade, coincidindo com o crescente interesse na gastronomia local e uso misto de ambientes urbanos. Para Zampollo $(2013$, p.184) a produção e o consumo de alimentos "desempenham um papel altamente visível e vital na vida pública das cidades, como também na criação de espaços públicos hospitaleiros. O alimento atua como veículo para facilitar a sociabilidade nos espaços urbanos". Vedana (2015) refere os eventos gastronômicos de rua não só como transformadores de espaços públicos, como também eventos promotores da conexão com chefs, como forma de aprendizado sobre gastronomia, como criadores de valor e como símbolo de estilo de vida e identidade. Em pesquisa realizada recentemente, Vedana (2015) identifica as motivações para a participação nesses eventos entre as quais destaca: estar com amigos, ocupação de espaços públicos, sair da rotina, conhecer novos pratos gastronômicos, valorizar e ter contato com os chefs, a informalidade, o custo acessível e a curiosidade. Considera-se, portanto, que para a cidade esta combinação entre comida de rua, evento e território é um tema que justifica o olhar reflexivo sobre esta prática.

No Brasil, entretanto, muitas cidades se mostram despreparadas, apresentando políticas locais inadequadas no trato destes eventos, por vezes até inviabilizando-os. Neste sentido identificam-se relações dificultadas por um contexto de interesses que simultaneamente não favorece o diálogo, nem tampouco facilita o consenso. Temos neste ecossistema o empreendedor, que quer oferecer o seu produto/comida; os moradores e utentes habituais da rua onde ocorrerá o evento; a prefeitura, que através da vigilância sanitária e do gerenciamento dos espaços públicos regulamenta tanto a comida quanto o local onde ela será oferecida; e o público consumidor, que deseja usufruir o evento, a comida e o espaço público. Avaliando este contexto, estaríamos diante de um problema comum de gestão urbana? Entende-se que não. Conforme bem observa Jacques (2015, p.9) "sabemos que as ferramentas, instrumentos e métodos ligados ao projeto, sobretudo em urbanismo, ainda herdados em boa parte do movimento moderno em arquitetura e urbanismo, são insuficientes para compreender a complexidade da cidade contemporânea".

\subsection{Street food e cultura de projeto}

Verifica-se neste aspecto a necessidade de uma abordagem diferenciada, onde a presença e intervenção do design estratégico surge como facilitadora das relações a fim de que um evento de comida de rua seja idealizado, discutido e planejado de maneira conjunta e colaborativa. Para Franzato, "as competências técnicas de design transformam-se em plataforma transdisciplinar que sustenta a convergência dos especialistas e dos demais atores que integram essa produtiva rede de colaboração. " (FRANZATO, 2015, p.174). Entende-se que a principal contribuição do design estratégico é justamente a organização contínua destas relações, objetivando uma evolução sustentável e que seja de proveito de todos os implicados neste processo. 
A compreensão a respeito destes eventos urbanos, não apenas como sendo um projeto a ser solucionado, mas, sim, como um problema a ser compreendido, torna-se pertinente a esta discussão. Conforme De Moraes, "o design se apresenta bem mais que o projeto [...] alargando o seu raio de ação próximo ao complexo conjunto de atividades compreendidas em sua concepção" (DE MORAES, 2010, p.67). Neste momento em que um primeiro entendimento do problema passa a ser o ponto de partida para a abordagem de sua condução, um instrumento desponta como facilitador da relação entre seus atores. Segundo Meroni, o design estratégico utilizase dos cenários como ferramenta para visualizar onde ir (MERONI, 2008, p.34). Conforme a própria autora frisa, "design estratégico é sobre construção de cenários". Freire resume esta relação dizendo que,

A construção de cenários é uma ferramenta essencial do design estratégico pois funciona como um estímulo ao diálogo entre os múltiplos atores de um projeto, ao mesmo tempo que explora as potencialidades para a inovação tecnológica e social. Cenários projetuais são a maneira pela qual o design estratégico transforma visões coletivas em hipóteses plausíveis e compartilháveis, traduzindo informações e intuições em um conhecimento perceptível que favorece o diálogo. (FREIRE, 2015 p.27)

Esta mesma apreciação das relações e a condução de uma visão compartilhada através do design por meio de cenários é observada por Franzato, quando este afirma, passamos a citar,

... a capacidade de leitura e interpretação dos sinais emitidos pelo ecossistema, aliada à projeção por cenários, é o cerne dos processos de design, uma vez que permite considerar o regular, o evidente e o possível, mas também o imprevisível, o acaso, a deriva ou o erro. (FRANZATO, 2015, p.174)

Tomando, então, os cenários como instrumento de design, quais seriam suas particularidades e implicações diante da complexidade dos eventos de comida de rua em espaços públicos urbanos, considerando seus atores envolvidos? Esta é a questão que o presente artigo se propõe a refletir.

\section{ANTECIPANDO NECESSIDADES}

Os ajustes da cidade movidos por novas manifestações sociais exigem interpretações coerentes e contemporâneas para uma problematização adequada. Como já sugerido anteriormente por Jacques (2015), devemos encarar novos desafios através de abordagens condizentes com o nosso tempo. Neste contexto e numa articulação com a natureza implícita nas street food, torna-se pertinente encontrar o espaço no qual um olhar segundo uma cultura de projeto resultará num importante vetor para promover a resolução deste problema. Neste aspecto, Manzini (2007, p.15) reforça as habilidades do designer estratégico como gerador de colaboração entre diversos atores, participação na construção de visões e cenários comuns, concepção de sistemas articulados de produtos, serviços e comunicação. Entre as ditas capacidades específicas do designer, Zurlo (2010) aponta três como particularmente 
funcionais para a ação estratégica: ver, prever e fazer ver. A capacidade de ver é entendida como a leitura orientada dos contextos, uma observação ampliada e que permite a compreensão sistêmica. Já na capacidade de prever, temos na antecipação crítica do futuro sua dimensão criativa mais latente. E, por fim, a capacidade de fazer ver trata de tornar visíveis cenários futuros. Esta última, segundo Zurlo (2010), "é a capacidade que, mais do que as outras, suporta a ação estratégica, visto que torna visível o campo do possível e é um instrumento potente de aceleração do processo de decisão". Se diante da análise de um problema a compreensão e aceitação da situação presente já não é um processo fácil, tratar de hipóteses futuras igualmente não o é. A discussão a respeito de um panorama que se desenha - ou deve ser desenhado muitas vezes traz à tona problemas de comunicação desta rede de atores, visto que requer de mecanismos que tangibilizem suas visões pessoais para que se alcance o entendimento geral.

Originalmente criado como uma técnica para antever situações e elaborar estratégias de guerra, o planejamento por cenários teve sua importância confirmada pelo exército dos Estados Unidos diante da Segunda Guerra Mundial. Etimologicamente a palavra cenário encontra no termo latino scaenarum sua origem, significando 'o lugar da cena', ou o lugar onde acontece uma determinada situação, seja ela real ou hipotética. Conforme Hartmann (2013, p.48), "com diversas aplicações no teatro, na música, na dança e no cinema, os cenários conectam dois mundos: o mundo real e o mundo imaginário. Na passagem da arte para as organizações, os cenários passam a configurar um modo de pensar que conecta o presente e o futuro". Independente da área em que está sendo aplicado, o objetivo do uso dos cenários é fazer ver um ou vários futuros possíveis. Atualmente, este instrumento já é uma estratégia consolidada e recorrente, considerado de grande importância por muitas empresas, agências governamentais e organizações comunitárias por suportar o pensamento a longo prazo (HARTMANN, 2013, p. 52).

\subsection{Cenários, formas e processos}

Como instrumento de design, a construção de cenários apresenta várias formas ou processos. Quanto ao seu momento de concepção, os cenários "são construídos através de informações e estímulos provenientes da análise do contexto externo ao ato projetual" (HARTMANN, 2013, p. 60). Quanto à materialização de sua entrega ou resultante, os cenários ganham eficácia quando apresentados "através de visualizações expressas em diagramas, histórias em quadrinhos, animações, vídeos, slides e mídias similares" (KUMAR, 2013, p.252). Porém, este instrumento não se resume a esta equação descrita, sendo desta forma pertinente o alcance de uma análise detalhada. Na literatura, diversos autores já contribuíram com pesquisas sobre o processo de construção de cenários. Entre outros destacaremos neste primeiro momento três referências dedicadas ao tema, com seus pontos de vista apresentados de maneira sucinta: Manzini e Jégou, Celaschi e Deserti, e Jégou et al.

Para Manzini e Jégou, a metodologia para construção de cenários corresponde a uma relação entre duas etapas, uma primeira denominada de Preparation Phase, e num segundo momento uma outra fase designada de Workshop Process. Na etapa de preparação temos as pesquisas que embasam e precedem o projeto. É o momento de 
exploração e conhecimento. Na etapa de processo de workshop, temos os processos indutivos e dedutivos que irão estabelecer e criar os cenários. Nesta metodologia de Manzini e Jégou, observamos uma fase divergente, onde abrem-se possibilidades através do conhecimento de diversos pontos de vista, e uma outra convergente, onde se busca encaminhar, ou convergir, estes pontos de vista para um objetivo comum ou ideal (HARTMANN, 2013, p.61). Já na abordagem de Celaschi e Deserti, a metodologia da construção de cenários inicia enquanto metaprojeto. Para estes autores, o processo compreende quatro etapas: a análise do contexto, onde incluem-se o mercado e as variáveis que tensionam a sociedade; os cenários, como resultante de uma fertilização cruzada entre tendências contemporâneas e o comportamento humano; as visões, elaboradas através de mapeamentos de polaridades; e, por fim, a geração de conceitos, onde serão encaminhadas as soluções. Conforme Hartmann (2013, p. 66), estes autores sustentam que a construção de cenários é mais importante do que a execução do projeto final. Isso em razão do entendimento de que cenários são uma base de reflexão, compartilhamento de conhecimentos e administração do horizonte para onde irá se encaminhar uma organização. Para François Jégou, a construção de cenários tem cinco etapas que não seguem necessariamente uma ordem: etapa de intenções, onde se define motivações projetuais; etapa de clusters, onde se elabora um agrupamento por semelhança das informações pesquisadas; etapa de polaridades, onde se identificam extremos ou balizas a partir de características percebidas como dominantes; etapa de mapa de orientação, onde escolhem-se as polaridades mais promissoras; e cenários, onde descrevem-se diretrizes de projeto através de referências visuais. (HARTMANN, 2013, p. 75).

Com este enfoque, os autores agora referidos apresentam metodologias na construção de cenários que, mesmo diferenciando-se no critério de corte por etapas identificadas conforme cada conceito, atendem essencialmente a uma mesma estrutura formada pela relação entre conhecimento, discussão e proposição. Embora ambos processos aqui descritos objetivem o viés prático do emprego do instrumento, a questão que envolve seu uso como promovedor de interação entre atores surge de maneira não tão enaltecida. Se para fins de desenvolvimento de projetos criativos esta propriedade eventualmente não está entre os principais benefícios do instrumento, para o nível estratégico ela figura como uma de suas principais finalidades. É importante também perceber que, dentro da trajetória do projeto, os autores citados posicionam a construção de cenários num momento intermediário do processo como um todo, onde inevitavelmente haverá uma correlação deste com outros instrumentos de design.

\subsection{O espaço de sobreposição com Cenários}

No contexto do processo criativo para geração de ideias e planejamento de projeto, Rosa (2013) apresenta uma série de instrumentos, identificados e elucidados a partir de sua pertinência operacional diante do design estratégico. A partir desta relação de instrumentos de design (ROSA, 2013) fez-se uma análise para detectar o cruzamento destes com o tema cenários, nos quais suas complementaridades reforçam e dinamizam tensões criativas. 
Verificamos então no Quadro 1 a relação de cada um destes instrumentos com o pensamento por cenários, seja abastecendo-o com insumos, seja dele se apropriando.

Quadro 1: síntese e relação com a natureza Cenários.

\begin{tabular}{|c|c|c|c|}
\hline Instrumento & O que faz & Como é aplicado & Relação com cenários \\
\hline Personas & $\begin{array}{l}\text { Identifica o perfil, } \\
\text { necessidades, desejos } \\
\text { associados aos usuários ou } \\
\text { atores de um processo. }\end{array}$ & $\begin{array}{l}\text { A partir de pesquisa } \\
\text { etnográfica, cria-se uma ou } \\
\text { mais pessoas com este perfil } \\
\text { síntese. }\end{array}$ & $\begin{array}{l}\text { Pode contribuir quando } \\
\text { inserido e avaliado diante } \\
\text { dos cenários propostos, } \\
\text { bem como auxiliar a } \\
\text { construí-los. }\end{array}$ \\
\hline $\begin{array}{l}\text { Análise } \\
\text { contextual }\end{array}$ & $\begin{array}{l}\text { Busca entender o contexto } \\
\text { geral do problema. }\end{array}$ & $\begin{array}{l}\text { Coletar informações, } \\
\text { documentos ou impressões } \\
\text { sobre todas as variáveis } \\
\text { pertinentes. }\end{array}$ & $\begin{array}{l}\text { Embasa a construção dos } \\
\text { cenários. }\end{array}$ \\
\hline Mapa de atores & $\begin{array}{l}\text { Sintetiza e dá sentido aos } \\
\text { dados coletados, } \\
\text { objetivando facilitar a } \\
\text { visualização da } \\
\text { complexidade entre } \\
\text { envolvidos }\end{array}$ & $\begin{array}{l}\text { Identifica-se os atores e os } \\
\text { agentes de suas interações. }\end{array}$ & $\begin{array}{l}\text { Contribui na identificação } \\
\text { dos envolvidos que devem } \\
\text { discutir os cenários. }\end{array}$ \\
\hline SWOT & $\begin{array}{l}\text { Analisa interna e } \\
\text { externamente o problema, } \\
\text { identificando forças, } \\
\text { fraquezas, oportunidades e } \\
\text { ameaças. }\end{array}$ & $\begin{array}{l}\text { Constrói-se um diagrama } \\
\text { separando ambiente interno } \\
\text { (forças e fraquezas) e externo } \\
\text { (oportunidades e ameaças). }\end{array}$ & $\begin{array}{l}\text { Contribui na construção de } \\
\text { cenários a partir da } \\
\text { identificação de } \\
\text { polaridades. }\end{array}$ \\
\hline Moodboard & $\begin{array}{l}\text { Painel visual que } \\
\text { representa uma atmosfera, } \\
\text { um conceito ou uma } \\
\text { referência estética. }\end{array}$ & $\begin{array}{l}\text { A partir dos valores-chave do } \\
\text { projeto, cria-se um painel } \\
\text { com imagens que o } \\
\text { representam. }\end{array}$ & $\begin{array}{l}\text { Auxilia no fazer ver os } \\
\text { cenários. }\end{array}$ \\
\hline Storyboard & $\begin{array}{l}\text { História visual para } \\
\text { estimular a discussão a } \\
\text { respeito de uma idéia, } \\
\text { pontos de contato ou } \\
\text { trajetórias. }\end{array}$ & $\begin{array}{l}\text { Desenha-se uma história, } \\
\text { considerando os personagens } \\
\text { principais interagindo em } \\
\text { uma situação. }\end{array}$ & $\begin{array}{l}\text { Auxilia no fazer ver os } \\
\text { cenários. }\end{array}$ \\
\hline $\begin{array}{l}\text { Manchetes do } \\
\text { futuro }\end{array}$ & $\begin{array}{l}\text { Textos jornalísticos fictícios, } \\
\text { nos quais a equipe se } \\
\text { projeta no futuro e imagina } \\
\text { o impacto da idéia } \\
\text { proposta. }\end{array}$ & $\begin{array}{l}\text { Escolhe-se um meio de } \\
\text { comunicação (jornal, tv, etc) } \\
\text { para criar uma estória. }\end{array}$ & $\begin{array}{l}\text { Tangibiliza uma idéia em } \\
\text { formato cotidiano, fazendo } \\
\text { ver um cenário. }\end{array}$ \\
\hline Cenários de uso & $\begin{array}{l}\text { Histórias hipotéticas criadas } \\
\text { para ilustrar um conceito } \\
\text { diante dos atores e o } \\
\text { contexto. }\end{array}$ & $\begin{array}{l}\text { llustra-se a estória através de } \\
\text { texto, teatro ou filme. }\end{array}$ & $\begin{array}{l}\text { Auxilia no fazer ver os } \\
\text { cenários. }\end{array}$ \\
\hline $\begin{array}{l}\text { Lego serious } \\
\text { play }\end{array}$ & $\begin{array}{l}\text { Explora dinâmicas entre } \\
\text { envolvidos através da } \\
\text { criação de um pensamento } \\
\text { tridimensional. }\end{array}$ & $\begin{array}{l}\text { Constrói e analisam-se } \\
\text { modelos dos ambientes a } \\
\text { partir de peças de Lego. }\end{array}$ & $\begin{array}{l}\text { Estimula a discussão e } \\
\text { interação ao construir e } \\
\text { fazer ver os cenários. }\end{array}$ \\
\hline Visioning & $\begin{array}{l}\text { Discute 'como seria se...' } \\
\text { antes de efetivamente } \\
\text { implementar uma idéia. }\end{array}$ & $\begin{array}{l}\text { Elaboram-se mockups, } \\
\text { cenários, vídeos e outros } \\
\text { elementos que tornem } \\
\text { visíveis a forma e o contexto } \\
\text { em que a idéia funcionará }\end{array}$ & $\begin{array}{l}\text { Utiliza-se dos cenários } \\
\text { como instrumento de } \\
\text { visualização de } \\
\text { possibilidades e } \\
\text { conseqüências da idéia } \\
\text { aplicada. }\end{array}$ \\
\hline
\end{tabular}

Fonte: Desenvolvido pelos autores 
Esta correlação entre instrumentos é característica da prática do design, onde a sua combinatória tem coerência na medida que atende de maneira adequada aos objetivos que estão em questão. No caso dos cenários percebe-se, diante dos demais instrumentos, características expressivas nomeadamente: como promovedor de uma linguagem compartilhada de visões e propostas e como um orientador da atividade projetual a partir do seu suporte a decisões. Se sua característica de representação visual proporciona a tangibilização de situações, é através das conjunturas problematizadas - ou em vias de serem problematizadas - que os cenários podem configurar-se como estrutura sistêmica de problema e solução, tendo na mediação entre fases de pesquisa e geração de conceito o momento da reflexão hipotética compartilhada. Se nos outros instrumentos verificamos níveis distintos de interação que atendem aos seus propósitos como fim, é justamente na construção de cenários que esta interação se mostra reveladora dos conflitos que porventura estão subentendidos.

\subsection{Os eventos imprevistos na cidade contemporânea}

Eventos como food parties ou food parks, por sua natureza efêmera, quando ocorrem em espaços públicos urbanos caracterizam-se por serem ambientes festivos. No sentido usado por Reyes (2015, p.23), “a ideia da festa marca as ações do território que são originárias por práticas sociais que se apropriam do espaço urbano na busca de efetivar um uso, uma ação, sem que isso constitua um valor econômico". Conforme, de seguida, complementa Reyes, "os usos, a festa, recuperam a ambiência social que efetiva o espaço - o verdadeiro sentido de territorializar". Esta prerrogativa do valor de uso é latente ao território enquanto espaço público, e dela depende sua essência. A questão que se apresenta é que, além deste mencionado valor de uso, encontramos nos eventos desta ordem o valor de troca, que se refere aos espaços comprados ou vendidos, ao consumo de produtos e dos próprios lugares. Este elo que liga ambos - valor de uso e valor de troca - reconhecemos como conflitivo, vista a divergência de interesses a considerar entre diferentes envolvidos.

Alinhado a este contexto de pensar o território (espaço público) pelo projeto (evento) sob a perspectiva estratégica (cenários), encontra-se em Reyes a contribuição mais adequada ao assunto. Compreendendo que a solução possível comanda a organização do problema, Reyes (2015, p.34) afirma que "é no espaço entre a construção de um problema e suas possíveis soluções que o processo se instaura", visto que é entre presente e futuro que teremos o momento de reflexão. $O$ autor considera três maneiras de organizar o pensamento através dos cenários: “(i) quando o futuro é visualizado e projetado para sua real efetivação, ou seja, uma perspectiva design-oriented; (ii) quando o futuro é antecipado para facilitar os novos procedimentos e poder modificar o modelo mental presente, ou seja, uma perspectiva causal; e (iii) quando o futuro é visualizado e projetado para ver o presente, suas tensões e conflitos, ou seja, uma perspectiva de projeto por cenários" (REYES, 2013, pg.97). 
Ao apresentar o uso do instrumento a partir da perspectiva de construção de projetos por cenários, Reyes $(2015$, p.14) propõe uma "abordagem que estrutura o problema de projeto, evidenciando os conflitos presentes no território urbano de maneira a expor os dissensos". Neste sentido, o instrumento ganha relevância como condutor de todo o processo, onde mais do que uma representação é uma maneira de construir um pensamento expondo seus conflitos no momento presente (REYES, 2013, p.32). Torna-se pertinente verificar no discurso do autor a significância do instrumento como um ativador da negociação e diálogo entre atores, fazendo emergir dissensos que reforçam o momento presente como a essência do projeto por cenários, vista a tensão inerente deste espaço-tempo. Hartmann (2013) enfatiza esta impressão e complementa destacando sua complexidade, ao dizer que

... os cenários passam a formar o espaço onde se criam as condições para que determinadas estratégias se cumpram. Nesse espaço, quanto maior for o número de atores que participam desse processo de negociação e decisão, mais complexo é o sistema e o contexto de referência e mais difícil será construir essa arena ou plataforma de interação. (HARTMANN, 2013, p.50 apud MANZINI, 2004)

Neste sentido então proposto por Reyes (2015), o instrumento cenários é utilizado como meio, e não como fim, pois objetiva a tensão do presente em lugar da idealização incerta do futuro. Em diálogo com o street food, é importante enquadrar este exercício - a construção de cenários - num território no qual a cidade se torna numa plataforma deveras espontânea, ou seja, uma numa relação de dependência com fluxos sociais, interagindo com novas formas de comportamento de improviso e adaptação de infraestruturas nômades. Esta natureza de uso implícito no ambiente urbano remete-nos para uma espécie de jogo de participação alternativo à cultura do consumo consolidado em velhos modelos instituídos. A prática do street food colocase assim como uma alternativa ao espetáculo passivo, ou seja, o principio de uma nova abertura para novos modelos de consumo, modelos estes que expressão a cultura do tempo livre, do jogo, da deriva no ambiente urbano não previamente codificável pela ortodoxia do projeto no qual e outrora criava tipologias de poder. Esta relação dialógica entre street food e espaço urbano remete-nos para um outro universo dedicado à experiência dependente do acaso, do uso lúdico articulado pela ordem dos fluxos inesperados presentes nas cidades de hoje.

Retomando a construção de cenários, a pergunta característica deste instrumento é: 'e se fosse...?'. É uma pergunta provocatória, no sentido de abrir discussões e expor posicionamentos diante das possibilidades que se desenham numa plataforma - a cidade - permeável à espontaneidade. É neste aspecto que a proposta de Reyes apresenta o uso do instrumento de maneira especialmente eficiente, pois de pouco adianta um esforço imaginativo de possibilidades se não houver consenso no reconhecer qual delas é a mais adequada ou promissora. Kumar (2013, p. 252) diz que "criar histórias sobre o futuro é também traduzir sistemas para narrativas que ajudem outros a entenderem como diferentes componentes trabalharão juntos". É contribuindo desta maneira que este instrumento assiste todos os atores envolvidos, ajudando-os a lidar com múltiplos sentidos e pontos de vista diante de um mesmo problema, estabelecendo entre eles uma conversação para compreender as forças que 
agem no plano desta disputa, visando não alcançar primeiramente uma visão compartilhada e convergência de objetivos, mas sim deflagrar seus posicionamentos.

\section{CONSIDERAÇÕES FINAIS}

Pensar o futuro é um processo de imaginar o que poderia ser. Para o design, está em jogo tornar visíveis ideias a fim de compreende-las e fazê-las motor de uma discussão produtiva, onde instrumentos apropriados permitem às pessoas mostrar, exteriorizar e compartilhar como pensam este futuro. A dificuldade reside não apenas na objetividade desta discussão, mas também no lidar com atores que supostamente não estão exatamente familiarizados com algumas técnicas e situações. Considera-se que na aplicação isolada ou combinada, os instrumentos referidos facilitam a dinâmica entre estes atores e constroem uma base relevante para o designer. Tido como um instrumento polivalente, o planejamento por cenários mostra-se apropriado tanto em processos externos quanto internos do projeto. Isto é, no plano metaprojetual, para organizar e estabelecer objetivos; na etapa intermediária, para sugerir possibilidades conceituais e servir de mecanismo dialógico e ainda na etapa final, para avaliação de resultados, tomada de decisões e proposição de aperfeiçoamentos.

No entendimento de que para eventos de comida de rua seja desejável contar com o planejamento estratégico, percebe-se no uso de cenários um dos instrumentos de design mais pertinentes a esta circunstância. Como bem aponta Reyes (2015), projetos que envolvem questões urbanas são complexos em decorrência da quantidade de variáveis e atores que os orbitam. Mais do que fazer ver hipóteses futuras, cenários provocam o diálogo. Atualmente, se desconhece a cultura da prática de discussão conjunta entre envolvidos nestes eventos. O avanço rápido de sua popularidade não apenas descortina a fragilidade e o despreparo da cidade em lidar com este tipo de situação caracteristicamente dinâmica, mas também evidência a perda de oportunidades ao não explorar este fenômeno sob vários aspectos, nomeadamente: como revitalizador de áreas urbanas degradadas; como ativador de turismo gastronômico; como evento festivo de uma comunidade; como articulador do micro-empreendedorismo; como promotor de legado em infraestrutura urbana; ou como criador ou incentivador da identidade de um território. Para viabilização de uma food party ou de um food park, observam-se iniciativas individuais diante de uma plataforma de regras impostas pelos órgãos regulamentadores, que, justamente por serem ações isoladas, perdem força e não atingem sua potencialidade. Há muito a ser feito.

Como estímulo a esta discussão, pode-se ensaiar este instrumento sendo posto em prática (Figura 1). 


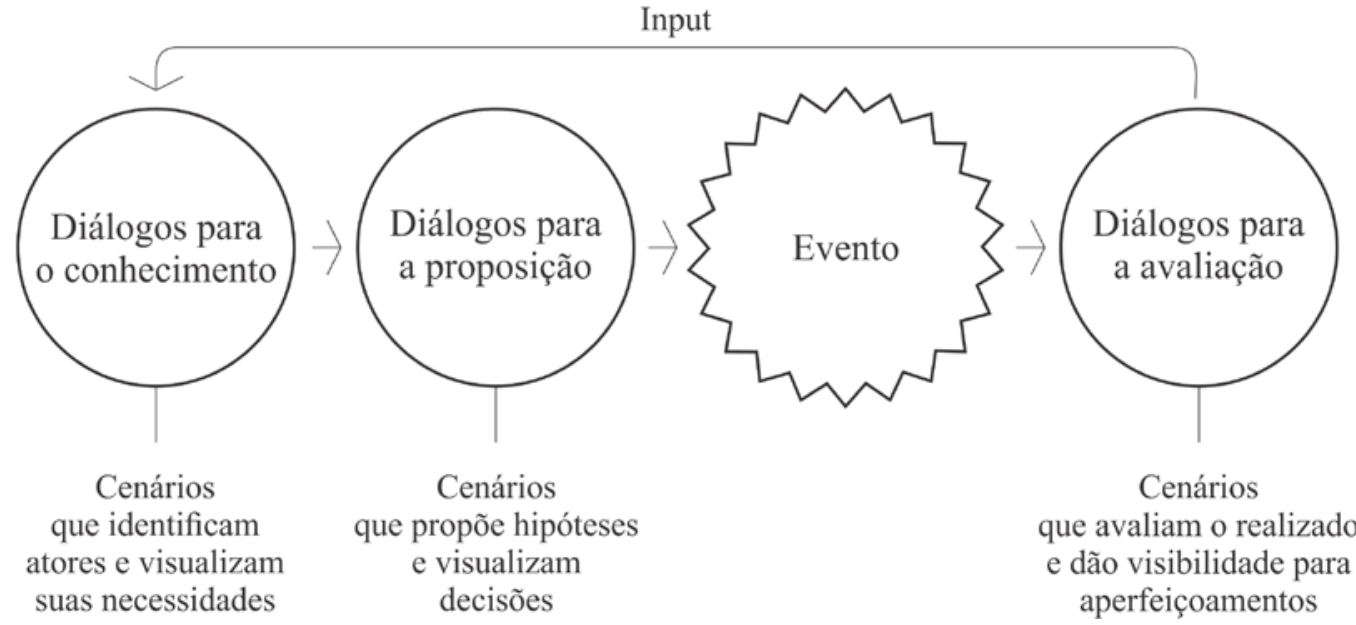

Figura 1. Cenários aplicado a diferentes momentos do planejamento Fonte: desenvolvido pelos autores

Primeiramente, em um momento de conhecimento, identificando e agrupando todos os atores interessados para um exercício de exposição de suas necessidades e expectativas. A partir destas, teríamos na construção de cenários a oportunidade do diálogo entre estes atores, exteriorizando seu posicionamento e clareando dissensos e consensos. Aqui cabe avaliar quais são as técnicas de representação ou visualização mais adequadas para a construção de cenários eficazes, visto que estamos tratando de atores não-designers. A busca por uma representação visual estimulante possivelmente enriqueça e facilite a discussão. A questão relevante é termos nos cenários a abertura de possibilidades de conversação. Posteriormente, em um momento de proposições, quando se tiver o planejamento ou o projeto do evento evoluído, este instrumento cenários novamente faz-se necessário como uma nova instância da discussão. Desta vez, diante de hipóteses elaboradas e tangíveis. De maneira ilustrativa e visual, os cenários agora apresentam-se aos atores que, novamente, estarão diante da oportunidade - talvez a mais relevante e construtiva de todas - para dissensos e consensos. Entretanto, possivelmente também estarão mais próximos de uma tomada de decisão adequada à maioria. Após o evento, a aplicação deste instrumento também surge como uma possibilidade enquanto promovedor da discussão sobre lições aprendidas ou aperfeiçoamentos futuros. Como um ciclo de aprendizado que se completa, um novo exercício de cenários neste estágio possibilita a discussão tanto a respeito de problemas identificados quanto de melhorias desejáveis. Adiante, numa próxima ocasião de natureza semelhante ou com os mesmos atores envolvidos, este exercício final contribui como input, ou ponto de partida, visto ser uma base de conhecimento já qualificada pela realidade prática.

Finaliza-se esta reflexão sugerindo que, para estas situações alusivas ao contexto dos eventos de comida de rua, a provocação da visão compartilhada é fundamental e indispensável, e, sua construção deve ocorrer de maneira sempre sistematizada. Planejar por cenários resulta assim em um desafio para uma compreensão das características ideais para a sua estruturação. É através do diálogo possibilitado por cenários que possivelmente pensar estes eventos de caráter efêmero 
permitirá habilitá-los a novas expectativas de todo um ecossistema difuso no território.

\section{REFERÊNCIAS}

DE MORAES, Dijon. Metaprojeto como modelo projetual. Strategic Design Research Journal, 3(2). Porto Alegre: Unisinos, 2010.

FRANZATO, Carlo; DEL GAUDIO, Chiara; BENTZ, Ione; PARODE, Fabio; BORBA, Gustavo; FREIRE, Karine. Inovação cultural e social: design estratégico e ecossistemas criativos in Design estratégico para a inovação cultural e social. Karine Freire (org). São Paulo: Ed Kazuá, 2015.

HARTMANN, Patricia. Cenários: uma tecnologia para suportar a complexidade das redes de projeto. Dissertação de mestrado. Unisinos. Porto Alegre, 2013.

JACQUES, Paola. O projeto como processo (Prefácio) in Projeto por cenários: 0 território em foco. Paulo Reyes. Porto Alegre: Ed Sulina, 2015.

KUMAR, Vijay. 101 Design methods: A structured approach for driving innovation in your organization. New Jersey, US: Ed Wiley, 2013.

MANZINI, Ezio. A laboratory of ideas: Diffuse creativity and new ways of doing in Creative Comunities. Anna Meroni. Italy: Ed PoliDesign, 2007.

MERONI, Anna. Strategic design: where are we now? Reflection around the foundations of a recent discipline. Strategic Design Research Journal, v.1, n.1, Dec 1, p.31-38. 2008.

REYES, Paulo. Projeto por cenários: 0 território em foco. Porto Alegre: Ed Sulina, 2015.

ROSA, Mirela; FREIRE, Karine; BORBA, Gustavo. SOS Criativo: Kit para explorar, criar e testar idéias. Porto Alegre: Unisinos, 2013.

VEDANA, Simone; PASLAUSKI, Carolline; ROOS, Erica; SCHIAVI, Cristiano. Comida em movimento: o significado simbólico dos eventos gastronômicos de rua e food trucks em Porto Alegre. XXXIX Encontro da ANPAD. Belo Horizonte MG, setembro de 2015.

ZAMPOLLO, Francesca. Food and design: space, place and experience (Editorial). Hospitality \& Society, v. 3, n. 3. Intellect Ltd Editorial, 2013.

ZURLO, Francesco. Design Strategico. In: XXI Secolo, vol. IV, Gli spazi e le arti. Roma: Enciclopedia Treccani. 2010. 